\title{
The Teaching Reform of Metal Technology Course
}

\author{
Jingling Wang \\ Tianjin University of technology and education, Tianjin 300222, China \\ 28759400@qq.com
}

Keywords: curriculum system; metal practice; case library; comprehensive experiments

\begin{abstract}
The course of metal technology is a professional basic course, which mainly introduces the composition, organization, performance and application of materials and it's forming process, closely related to engineering practice. Based on the concept of "integrity of teaching, learning and practice", this paper establishes a new curriculum system. Starting from the experiment and training session, the curriculum and metalworking practice are closely combined. Through the development of case library and comprehensive experiments, students' practical ability and comprehensive engineering quality are improved.
\end{abstract}

\section{Introduction}

The national long-term education reform and development plan (2010-2020) is clearly stated in chapter 6 of education: the state should energetically develop the professional education, which will focus on improving the quality, and train qualified workers for economic and social development and strengthen the "double division" teachers team. Tianjin University of technology and education, as a teaching and training school for teachers of vocational schools, has the dual task of training education teachers and applied talents, implementing integrated teaching is an important approach. The so-called integrated teaching is the combination of theoretical teaching, practice teaching, production service and scientific and technological development in teaching activities. Teaching theoretical knowledge in practice, and studying technique in the application process. This is in line with the idea of "integrity of teaching, learning and practice", which is advocated by the great people's educator Tao Xingzhi. Essence of "integrity of teaching, learning and practice" is to learn according to doing process, and teach according to learning process $[1,2]$.

The course of metal technology is a professional basic course in the research of the comprehensive technique of manufacturing metal parts. The course focuses on the relationship of composition, organization, performance and application for material, The regularity of various process methods and their application and interconnection in mechanical manufacturing, process and construction technology of metal parts, The influence of metal material properties on processing technology, and The synthesis of process methods etc. The course is an important course for improving students' basic literacy and training students to solve practical problems in engineering, It has the characteristics of high content, strong concept and strong engineering practice. In general, students have less professional experience, less knowledge of engineering application, and lack of perceptual knowledge, therefore, they cannot understand the knowledge of books from the perspective of engineering practice. For example, knowledge such as metallographic and mechanical properties of various metals, heat treatment process, casting, forging, welding process, etc., can only be truly understood by practice. In the course of the course of metal technology, this paper has carried out the research on teaching practice from the aspects of classroom teaching, experiment and practice.

\section{The connotation of the "integrity of teaching, learning and practice"}

In the teaching process of "metal technology" course, The author understand the idea of the education of "integrity of teaching, learning and practice" from four levels [3,4]. First, teaching is divided into three levels, from teaching to teaching knowledge to teaching students, then teach student 
how to learn. To teach student how to learn is the highest level of teaching. That means to the teacher does not teach the ready-made solution, but how to find the solution for some problem. Secondly, the teacher's teaching method should be based on the student's method, from the students' point of view, prepare the teaching content and design the teaching process, arouse the student's interest in study. To make students happy to learn, from "to learn" to "I want to learn". Third, the core is "do", learning on the basis of doing, teaching on the basis of doing , and learning can't be separated from engineering practice. Four is to teaching benefits teachers as well as students. Teachers keep learning in the process of teaching, to trace their knowledge back to the source and improve their professional competence and professionalism. Under the guidance of the above ideas, the "integrity of teaching, learning and practice" is applied to the teaching of metal technology, and the concrete implementation method is produced.

\section{The Applying of "Integrity of Teaching, Learning and Practice"}

\subsection{Course System based on "Teaching, Learning and Doing"}

Metal technology course has much content, concept, content abstract material structure, the theory of boring characteristics, combined with the students' engineering practical experience, teaching and learning of the course is very difficult, the teaching effect is not good[5]. In the general trend of teaching reform, the class period did not increase, and the content of the teaching increased, which brought higher demand to the teaching of the course. Accordingly, from the top design, based on the requirement of the professional foothold, geared to the needs of industry development trends, to build an specific curriculum content system is the key to solve the problem.

Zhejiang university party committee, deputy secretary of the Zou xiao-dong published "China manufacturing strategy and the engineering practice of education reform" and analyses the major trend of the international higher engineering education, it is suggested that the learning mode should be transformed from the traditional subject oriented knowledge system to the knowledge-building learning system which leads the problem. Therefore, the first priority of the course is to break the traditional knowledge system. The author according to the goal of talent cultivation, determine the course orientation, ability training and the knowledge structure of support relationship, establish a realistic demand ability oriented curriculum system.

The personnel trained in mechanical manufacturing will be engaged in the design and manufacturing of the products. Through the study of metallurgical technology courses, on the basis of the master the basic theory and knowledge of engineering materials, student understanding the composition, microstructure, properties and application of the material and the relationship between the processing method, So that students have a reasonable selection of engineering materials and forming technology, lay a foundation for mechanical parts design and manufacturing of learning, understanding machine, parts production and manufacturing process of the whole cycle.

The undergraduate of this major is more attention to skill, notice the docking of the post. The ability to develop new materials and new processes is not required, and the emphasis is on the ability to apply skills directly to the production line. So in this course, the basic theoretical knowledge of the material is appropriate. The course content system of "metal technology" is shown in figure 1. The structure of the content of the course has weakened the contents of the structure of the material, and the emphasis is on the selection and application of engineering materials and the understanding of the process of hot processing. The course system streamlined the structure of the crystal and the content of the phase diagram, while strengthening the heat treatment, the common engineering materials and the materials and the process are directly related to the ability. In addition to the content on the increase or decrease in adjustment, more attention is payed to the integration of the depth of the content of each module, both meet the ability training requirements, and ensure the completion of the subject knowledge system. 


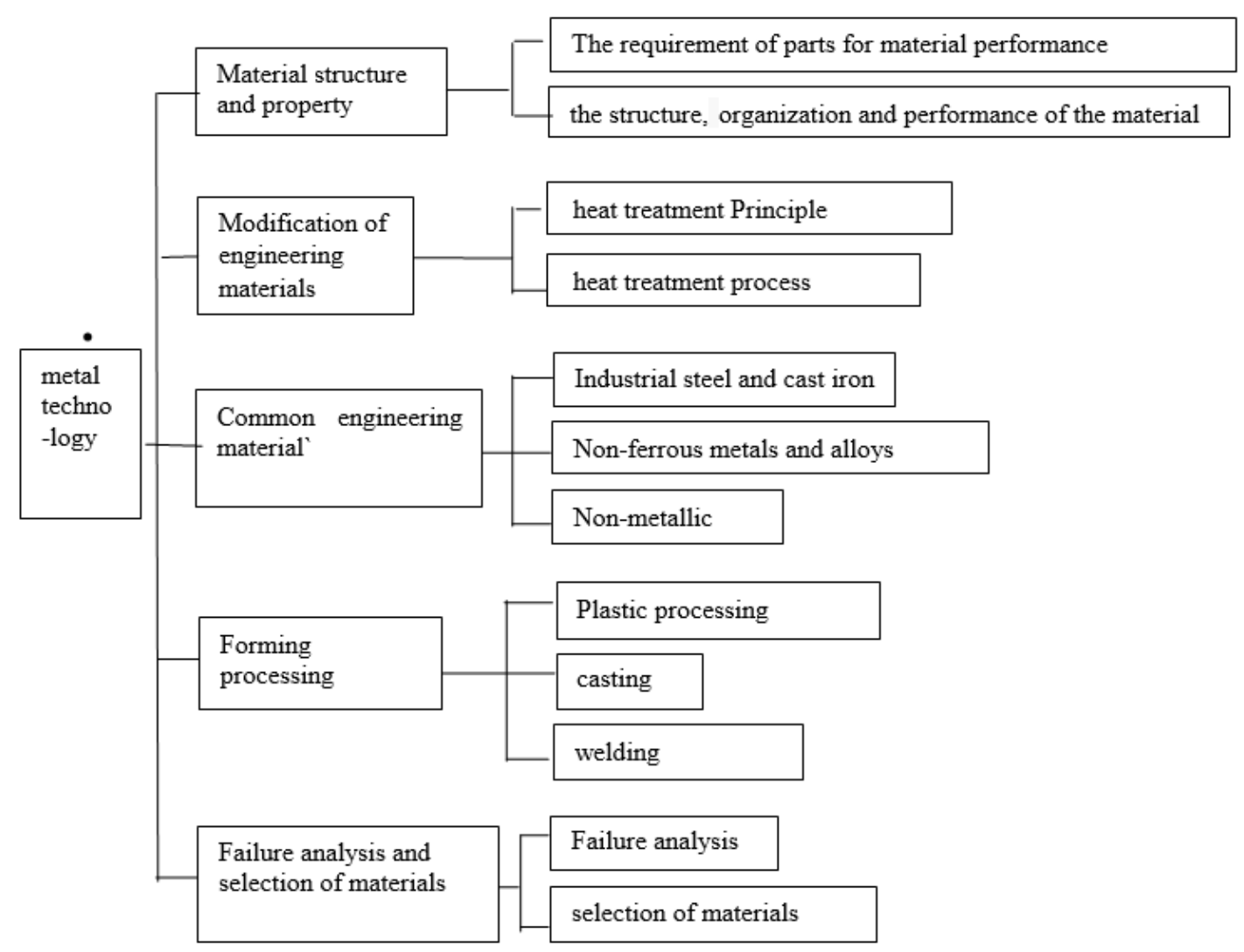

Fig. 1 system of course

\subsection{The Implementation of 'Do' Combined with Practice}

Practice teaching is an important part of the teaching process. In practice teaching, we should explore the diversity of teaching forms, combine theoretical teaching and practice teaching, improve the teaching effect and cultivate students' comprehensive ability [6].

1) Combination with Metalworking practice

Metal technology course is combined with metalworking practice, Theoretical teaching and metalworking practice alternated. Comprehensive engineering training projects are designed to implant the metal practice into the metal technology course. The projects include heat treatment, microstructure observe, and process which are according to actual product product process. The peojects cover all the knowledge of metal technology course. That enhance the engineering of the course and make the practice of metalworking practice have strong theoretical knowledge guidance. However, the implementation of the project teaching in the teaching, the field, the teaching requirements are relatively high, is difficult to guarantee.

2) The development of comprehensive experiments

The integration teaching can be achieved through the design of integrated, coherent, and closely connected experiments. for example, the production process of a low carbon steel part is to cast a blank, then heat treatment and then the forging pressure. The production process covers the main knowledge of process and heat treatment in the process of metal technology. At the same time, the object of the experiment was also provided for the change observation of casting tissue, forging pressure and heat treatment. This part is set as the object of metalworking practice casting and forging, and its casting, the practice part of forging and pressing process is combined with the forming part of the process of metal technology. This kind of model can be operable, which can enhance the relationship between theory and practice, enrich the purpose of engineering training, and benefit the cultivation of applied talents with high quality of comprehensive engineering [6].

Combining theoretical teaching with practice teaching through comprehensive experiment, to adapt to the modern manufacturing technology in the engineering education for engineering materials, the basic requirement of material forming and manufacturing process as a starting point, fully embodies the knowledge in curriculum construction of crossover and integration application. The combination of 
comprehensive training, theoretical teaching and practical teaching is an attempt to integrate curriculum construction with engineering application training

\subsection{Teaching Content Processing}

Based on the principle of from the student's research method to design teaching, teaching material as a blueprint, guided by the teaching outline, the teaching contents to make the necessary processing and refining, four principles are putted forward, namely, visualization, structured, and problem-based, and engineering-based.

\section{1) Visualization}

Metal technology course involves more abstract concepts and some transition within the material which are invisible. Because students have limited contact with production practice, the process of casting, forging and welding is also relatively abstract. From the perspective of student learning, abstract knowledge is difficult to understand, difficult and boring to learn. Turning these abstract knowledge into concrete, visible, will benefit students' learning. Making pictures, video, simulate animation and other teaching materials, using the multimedia teaching method, enrich the teaching resources, are good way to transform abstractions into concrete images.

2) Structured

Some research shows that the main difficulty in memory of knowledge is searching rather than storage. In metal course, the content of knowledge is developed into structural frame diagram to facilitate students' understanding of memory. The teacher gives the basic structure of the student discipline, namely the basic concept, principle, law, thought method and internal relation of the subject. The knowledge tree or the form of the compendium signal can present and reveal the inner relation of the knowledge structure effectively.

\section{3) Problem-based}

The content of the teaching is presented to students in the form of questions, which can lead to students' thinking and learning interest. The setting of such questions should be simple, direct and close to real life. For example, when explaining the principle of brazing, let the students think about how the computer's motherboard components are connected. And then explain process of brazing

4) Engineering-based

Engineering cases are introduced in teaching. Use engineering cases to carry the knowledge. Students solve problems, and the process of completing tasks is the process of learning. The problems that exist in the process of new technology and new technology are used as cases, To guide students to develop new knowledge application ability. This kind of teaching mode has high requirement for teachers 'professional knowledge, normal ability and teaching attitude.

\subsection{Establish Level Teaching Case}

Organize the teaching according to the study law, gradually, establish the study library, which is divided into four levels. From knowledge, skill to engineering practice ability to cultivate excessive and Promote students to apply what they have learned in practice. The first level is the preview question, which is to stimulate interest, to use simple and practical examples of life, to guide students to preview. The second level is a class discussion topic, which is to carry out the knowledge of the classroom, promote the understanding of the course knowledge, and guide students to think and learn actively and participate in the classroom. The third layer is an after-school homework problem, which is to review the knowledge already learned, and to further expand, to guide students to access the data, and to cultivate the ability of independent thinking and independent thinking. The fourth level is the stage synthesis title, which is closely combined with engineering practice to cultivate students' engineering thinking, open topic setting, and cultivate students' innovative consciousness.

\section{Summary}

Tao xingzhi as a great educator in China, put forward the idea of integrity of teaching, learning and practice. Under the guidance of this idea, according to the training goal, the curriculum system, practice and teaching mode are developed. 


\section{References}

[1]. Hou Huaiyin, Li Yanli. Review of the integrated teaching method, Curriculum, teaching material and method, Vol.33 No.8(2013):17-23

[2]. Yu Hao, Yu Jing. Curriculum design based on teaching learning Doing, Journal of Huang gang polyechnic, Vol.13 No.6(2011):34-39

[3]. Tao Xingzhi.Ten words foe education[M].A complete collection of tao xingzhi,Vol.4, Chengdu: SiChuan education press, 2009,12.

[4]. Zhang Jianxin. Innovation and Practice for the undergraduate curse teaching of "Technology of metal", Education teaching forum, 2014.11:138-139.

[5]. Shi Xiaoliang, Wang Yu, Peng Zhao. Teaching reform and practice of metal technology course based on teaching and scientific research, 2014.07:45-46

[6]. Song Ge, Semi virtual project teaching of metal technology based on CDIO concept, China Metallurgical Education, 2014.03:3-6 